\title{
Stress-enhanced Cu-to-Cu Bonding for MEMS Packaging
}

\author{
Jenn-Ming Song, ${ }^{1,2,3 *}$ Sin-Yong Liang, ${ }^{1}$ Zong-Yu Xie, ${ }^{1}$ Po-Hao Chiang, ${ }^{1}$ Shang-Kun Huang, ${ }^{4}$ \\ Ying-Ta Chiu, ${ }^{4}$ David Tarng, ${ }^{4}$ Chih-Pin Hung, ${ }^{4}$ and Jing-Yuan Lin $^{5}$ \\ ${ }^{1}$ Department of Materials Science and Engineering, National Chung Hsing University, Taichung 402, Taiwan \\ ${ }^{2}$ Research Center for Sustainable Energy and Nanotechnology, National Chung Hsing University, \\ Taichung 402, Taiwan \\ ${ }^{3}$ Innovation and Development Center of Sustainable Agriculture, National Chung Hsing University, \\ Taichung 402, Taiwan \\ ${ }^{4}$ Advanced Semiconductor Engineering Group, Kaohsiung 811, Taiwan \\ ${ }^{5}$ Microsystems Technology Center, Industrial Technology Research Institute, Hsinchu 310, Taiwan
}

(Received April 2, 2018; accepted June 15, 2018)

Keywords: MEMS packaging, $\mathrm{Cu}-$ to-Cu bonding, air plasma bombardment, formic acid vapor

To replace $\mathrm{Al}-\mathrm{Ge}$ eutectic bonding, low-temperature direct $\mathrm{Cu}$-to- $\mathrm{Cu}$ bonding was developed in this study. Lattice distortion and thus a hardened $\mathrm{Cu}$ subsurface conducted by air plasma bombardment, instead of surface activation, contributed to a compressive residual stress component and an accelerated $\mathrm{Cu}$ atom diffusion. This gave rise to a significant improvement in direct $\mathrm{Cu}$ bonding strength. Subjected to 3-min plasma exposure and the following deoxidation treatment using catalyzed formic acid vapor, robust $\mathrm{Cu}$-to- $\mathrm{Cu}$ bonding with the joint strength up to $31.7 \mathrm{MPa}$ can be achieved when bonded at $250{ }^{\circ} \mathrm{C}$ for $5 \mathrm{~min}$ under a loading pressure of $10 \mathrm{MPa}$ in $\mathrm{N}_{2}$.

\section{Introduction}

Al-Ge eutectic bonding has been developed by InvenSense for inertial measurement unit (IMU) sealing. ${ }^{(1,2)}$ The Al-Ge bonding process needs to be performed at $450{ }^{\circ} \mathrm{C}$ or above, and the bonding period is at least $70 \mathrm{~min}$. To achieve IMU sealing at low temperatures within a short time, in this study, we proposed a modified direct $\mathrm{Cu}$ bonding with no high vacuum. The process temperature is aimed to be $250{ }^{\circ} \mathrm{C}$ or even below. Bonding time can be decreased from 70 to $5 \mathrm{~min}$. Complicated thin film deposition can thus be omitted.

Traditional direct $\mathrm{Cu}$ bonding is usually performed at temperatures above $350{ }^{\circ} \mathrm{C}$ under high vacuum $\left(\sim 10^{-3}\right.$ Torr). ${ }^{(3)}$ A postannealing is necessary to eliminate the bonding interface and thus increase joint strength. ${ }^{(4)}$ Recently, modified processes to enhance direct $\mathrm{Cu}$ bonding have been suggested. ${ }^{(5-11)}$ Fujitsu Laboratories proposed a surface grain refining pretreatment, which combines diamond cutting, organic acid vapor, and vacuum ultraviolet treatments. ${ }^{(12,13)}$ Diamond cutting is performed to acquire a fine crystal layer underneath the surface, and formic acid vapor removes $\mathrm{Cu}$ oxides on the cut surface. A subsequent vacuum ultraviolet irradiation dissociates residual formate. Through this combined process, successful bonding can be 
carried out at $175^{\circ} \mathrm{C}$. It was proposed that fine grains underneath the diamond bit-cut surface accelerate $\mathrm{Cu}$ atom interdiffusion between two faying faces.

On the basis of the above surface modification concept, in this study, we combine air plasma bombardment with a following catalyzed formic acid vapor treatment, which aims to achieve robust $\mathrm{Cu}$-to-Cu direct joints at $250{ }^{\circ} \mathrm{C}$ or below for the application of MEMS sealing. Instead of surface activation, the low-vacuum air plasma bombardment conducted is to control the surface physical characteristics of the faying face, and formic acid vapor catalyzed by Pt is adopted for deoxidation prior to thermal compression bonding.

\section{Experimental Procedures}

Squared silicon chips with $2.1 \times 2.1 \mathrm{~mm}^{2}$ dimensions and 550-nm-thick sputtered $\mathrm{Cu}$ films on the Si chips were prepared. The $\mathrm{Cu}$ patterns were of square shape for which the width of the sealing frames was $136 \mathrm{~nm}$. Low-vacuum air plasma bombardment and formic acid vapor treatment were carried out in sequence before bonding. With respect to air plasma bombardment, a low-vacuum plasma cleaner (Harrick PDC-001) with an input power of 200 $\mathrm{W}$ and a maximum RF power of $30 \mathrm{~W}$ was used. Plasma bombardment was performed on the faying face under 0.25 Torr, which was much higher than the vacuum pressure in the plasma process for surface activation $\left(10^{-3}-10^{-4}\right){ }^{(14,15)}$ Plasma treatment time was set as 1,3 , and $5 \mathrm{~min}$. After plasma treatment, the samples were then stored in ambient air for hours.

The surface roughness and hardness of the samples before and after plasma exposure were measured using an atomic force microscope (AFM; Bruker Dimension Icon, tapping mode) and a nanoindenter (Hysitron TriboLab), respectively. AFM was adopted to obtain the average surface roughness of the bonding face, $R_{a}$. The scanning range was $500 \times 500 \mathrm{~nm}^{2}$. Nanoindentation was performed to measure the hardness and Young's modulus along the through-thickness direction. The indenter was pressed into the specimen up to $100 \mathrm{~nm}$ with a penetration rate of $5 \mathrm{~nm} / \mathrm{s}$. The load-displacement data obtained were analyzed using the method of Oliver and Pharr to determine the hardness and elastic modulus as functions of the displacement of the indenter. ${ }^{(16)}$ In this study, the mechanical properties in the subsurface region, about $10 \mathrm{~nm}$ underneath the surface, were recorded. Each datum was the average of at least 10 tests. In addition, the residual stress on the bonding face before and after air plasma bombardment was also measured. The principles of X-ray diffraction (XRD) stress measurement are described elsewhere. ${ }^{(17)}$ Grazing incidence XRD (incidence angle of $3^{\circ}$ ) was with graphite monochromatic $\mathrm{Cu}$ Ka radiation at a scanning rate of $1 \%$ min with $2 \theta$ from 40 to 80. The $\mathrm{Cu}(111)$ diffraction peak was selected for investigation.

A vapor-assisted bonding system was equipped with a formic acid vapor generation unit and a treatment/bonding chamber with low vacuum. Formic acid vapor was generated by importing $\mathrm{N}_{2}$ gas into a formic acid solution. A mixed gas of formic acid vapor and $\mathrm{N}_{2}$ was dispensed by a spray nozzle filled with Pt catalysts isothermally heated at $200{ }^{\circ} \mathrm{C}$, which was placed between two bonding substrates. The distance between the nozzle and the two bonding pieces was about $6 \mathrm{~mm}$. Thermal compression was performed at 230 or $250{ }^{\circ} \mathrm{C}$ for 5 min under nitrogen atmosphere. Bonding pressure was maintained at $10 \mathrm{MPa}$. 
The shear strength was measured by breaking the bond between the joint specimens with a shear tool with a shearing rate of $0.2 \mathrm{~mm} / \mathrm{min}$. A bond tester (Cometech Testing Machines QC$506 \mathrm{M} 1)$ was used. The shear strength was determined to be the maximum load divided by the area of $\mathrm{Cu}$ patterns. Each datum was the average of at least five tests. The organic residues on the fracture surface were detected using a micro Raman spectrometer.

\section{Results and Discussion}

The AFM images and quantitative surface roughness data given in Fig. 1 reveal that air plasma bombardment resulted in a slightly rugged surface. $R_{a}$ increased from $0.8 \mathrm{~nm}$ (as-

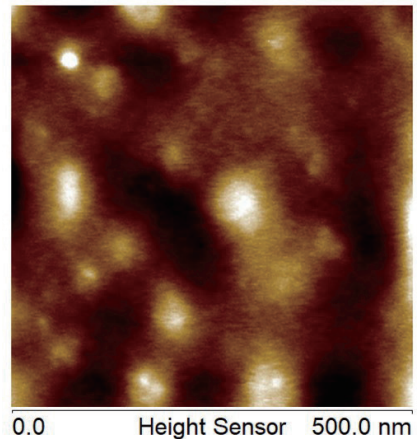

(a)

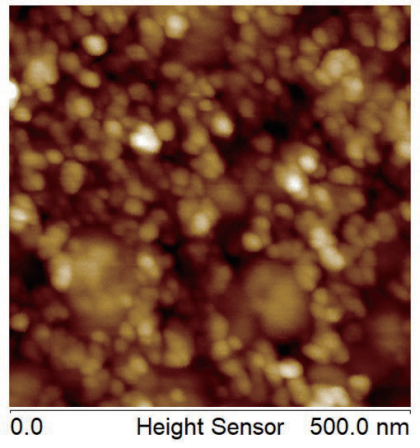

(c)

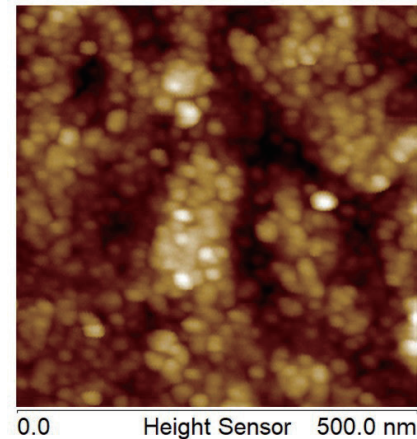

$8.9 \mathrm{~nm}$

$3.3 \mathrm{~nm}$

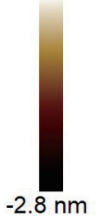

(b)

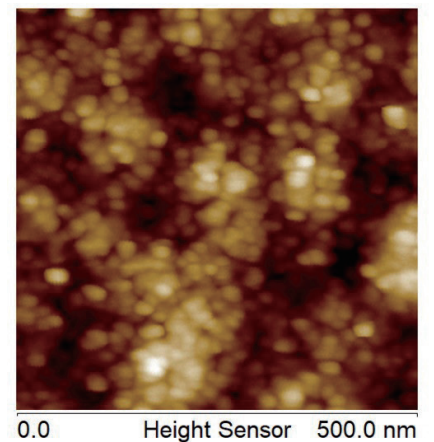

(d)

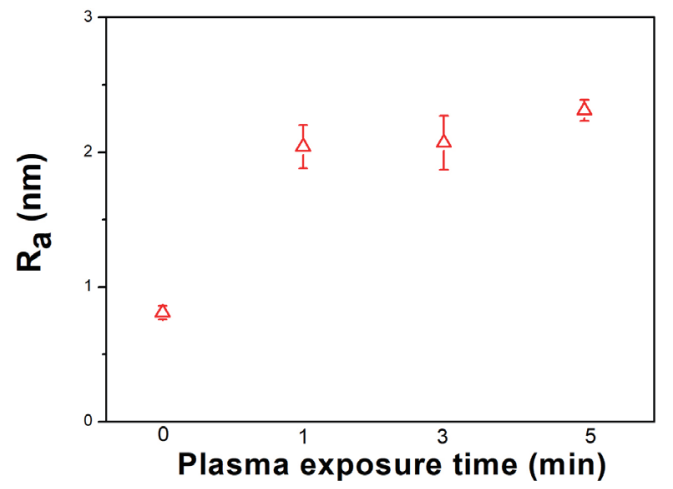

(e)

Fig. 1. (Color online) AFM images of plasma-bombarded $\mathrm{Cu}$ films: (a) 0, (b) 1, (c) 3, and (d) 5 min, and (e) quantitative surface average roughness data. 
received condition) to $2.0 \mathrm{~nm}$ (exposure for $1 \mathrm{~min}$ ), $2.1 \mathrm{~nm}$ (exposure for $3 \mathrm{~min}$ ), and then 2.3 $\mathrm{nm}$ (exposure for $5 \mathrm{~min}$ ). Nanoindentation was conducted on the $\mathrm{Cu}$ surface to analyze the mechanical properties of the pretreated $\mathrm{Cu}$. Figure 2 indicates the average hardness as well as Young's modulus obtained from $10 \mathrm{~nm}$ underneath the surface. Air plasma exposure can effectively harden the sample surface subjected to a short exposure period. Plasma irradiation can strongly increase the hardness from 2.9 to $5.9 \mathrm{GPa}$ ( 1 min plasma exposure) and then to the maximum value of $6.4 \mathrm{GPa}$ ( 3 min plasma exposure). However, an extended plasma exposure to $5 \mathrm{~min}$ resulted in a decreased hardness to $4.5 \mathrm{GPa}$. Likewise, with increasing exposure time, the Young's modulus changed from 140.4 (as-received state) to 192 (plasma exposure for 1 $\mathrm{min}), 208$ (3 $\mathrm{min})$, and $153 \mathrm{GPa}(5 \mathrm{~min})$. It can be deduced that plasma bombardment altered the surface mechanical features due to lattice defects and heat generation. ${ }^{(18,19)}$ The former causes work hardening (referred to as the 1- or 3-min-plasma-bombarded samples), and the latter leads to recovery (referred to as the 5-min-plasma-bombarded samples).

Thermal compression bonding can successfully join two $\mathrm{Cu}$ films at $250{ }^{\circ} \mathrm{C}$ or even below. Figure 3 shows the cross-sectional joint structure machined by focused ion beam of the sample subjected to 1 min air plasma bombardment, formic vapor cleaning, and then thermal compression bonding at $250{ }^{\circ} \mathrm{C}$, depicting a firm bonding between two fayed $\mathrm{Cu}$ films. The bonded samples were fractured by shear test and the maximum shear strengths were recorded. It was found that all the fracturing occurred at the bonding interface. As given in Fig. 4, with a prolonged plasma treatment, the joint strengths bonded at $250{ }^{\circ} \mathrm{C}$ were 18.5 (as-received), 30.2 ( 1 min bombardment), 31.7 ( 3 min bombardment), and $28.3 \mathrm{MPa}$ (5 min bombardment). When the bonding temperature was decreased from 250 to $230{ }^{\circ} \mathrm{C}$, the joint strength was clearly deteriorated. They were 8.7 (as-received), 17.3 (1 min bombardment), $18.8 \mathrm{MPa}$ ( $3 \mathrm{~min}$ bombardment), and 14.5 (5 min bombardment).

The aforementioned results reveal that subsurface hardness has a positive relationship with joint strength. On the other hand, the highest roughness value was only $2.3 \mathrm{~nm}$; therefore, the influence of surface roughness was not that pronounced. Plasma bombardment can clean the sample surface and activate the surface by forming broken bonds. However, it is considered

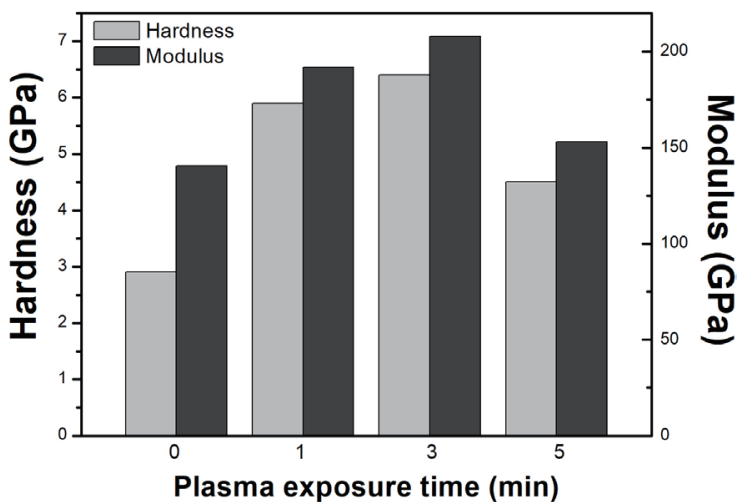

Fig. 2. Surface hardness and Young's modulus obtained from $10 \mathrm{~nm}$ underneath the sample surface subjected to different periods of plasma treatment.

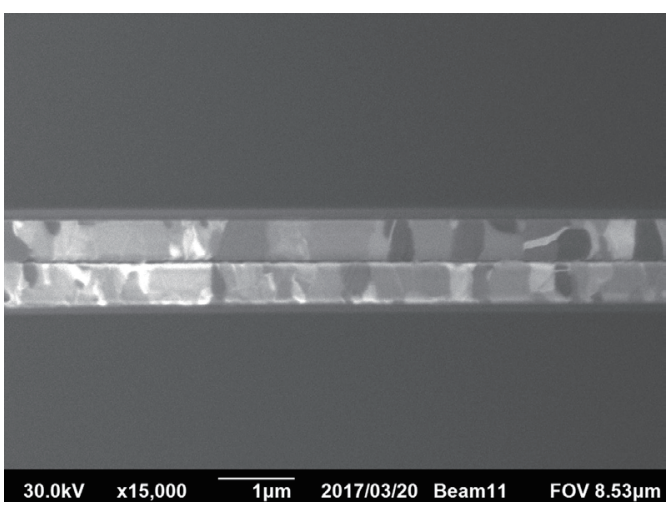

Fig. 3. Cross-sectional microstructure of the bonded sample (1 min air plasma bombardment). 


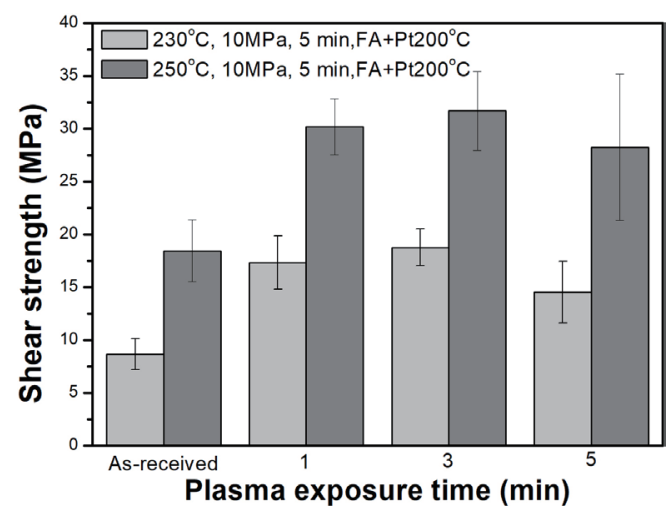

Fig. 4. Shear strength of sputtered $\mathrm{Cu}$ joints subjected to different air plasma pretreating, formic acid treatment, and thermal compression bonding at $230^{\circ} \mathrm{C} / 250^{\circ} \mathrm{C}$ under $10 \mathrm{MPa}$ for $5 \mathrm{~min}$.

that, in this case, the improvement in hydrophilicity would also be suppressed by prolonged storage in air ambient (hours in this study) or acid treatments prior to bonding. ${ }^{(20)}$

Figure 5 shows the residual stress calculated from the XRD results and the comparison of $\mathrm{Cu}$ self-diffusivity at as-received and 3-min-plasma-exposed states, respectively. The diffusivity estimation under stress conditions can be obtained using the equation below: ${ }^{(21)}$

$$
\ln \left(\frac{D}{D_{0}}\right)=\left(\sigma-\sigma_{0}\right) \frac{V^{*}}{k T}
$$

where $D$ is the diffusivity of $\mathrm{Cu}$ atoms under the set conditions, $D_{0}$ denotes the diffusivity of $\mathrm{Cu}$ at the as-received state, $V^{*}$ is the atomic volume of fcc- $\mathrm{Cu}, 1.3 \times 10^{-27} \mathrm{~m}^{3}$, and $\sigma$ and $\sigma_{0}$ represent the stresses before and after pretreatments, respectively. It was found that the residual stresses under the as-received conditions were under the tensile state. Air plasma bombardment brought about a raised compressive stress component. If the samples were exposed to air plasma for $3 \mathrm{~min}$, the tensile stress was reduced from 146 to $97 \mathrm{MPa}$. Based on the relative diffusivity data, a suppressed tensile stress gave rise to an increased $D / D_{0}$. With air plasma exposure for $3 \mathrm{~min}$, the self-diffusivity is about 1.53 times greater than those of the as-received samples.

In conjunction with our previous data related to the plasma bombardment effects on thermal compression bonding between two $\mathrm{Cu}$ blocks (Fig. 6), a relationship between residual stresses and joint strength can be derived. The positive contribution by a compressive stress component on direct $\mathrm{Cu}$ bonding can be demonstrated again.

The examination of the fracture surface using Raman spectrometers is illustrated in Fig. 7. The effect of $\mathrm{Pt}$ catalysis for formic acid vapor on the residual organics could be realized. The signals of $v(\mathrm{C}=\mathrm{O}), v_{a s} \mathrm{CO}_{2}{ }^{-}, v_{s} \mathrm{CO}_{2}{ }^{-}$, and $\mathrm{Cu}(\mathrm{OH})_{3}$ on the fractured surface for those subjected to formic acid vapor treatment catalyzed by Pt prior to bonding were much weaker than those with uncatalyzed vapor treatment. This leads us to believe that Pt can accelerate the dissociation of formic acid, which may be somehow beneficial for the long-term reliability of the directly bonded $\mathrm{Cu}$ joints. 


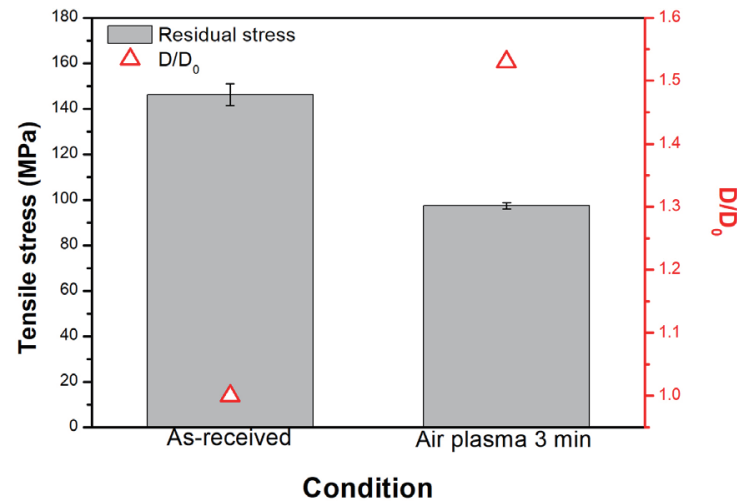

Fig. 5. (Color online) Estimated residual stress and diffusion coefficient of $\mathrm{Cu}$ atoms before and after air plasma bombardment.

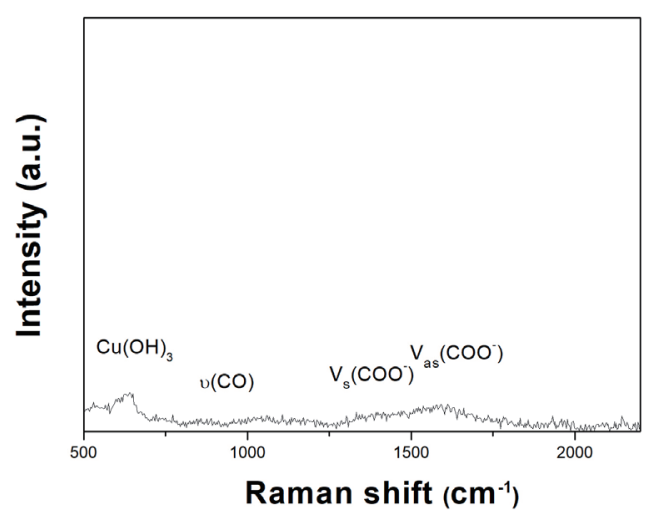

(a)

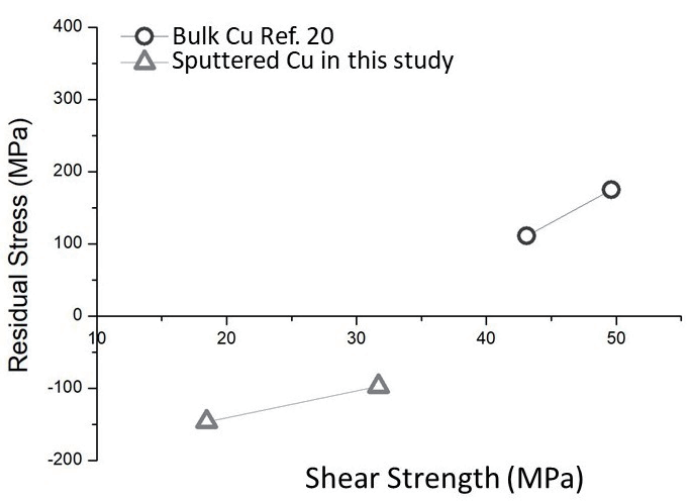

Fig. 6. Relationship between residual stress on faying surface and joint strength (positive stress value denotes compressive stresses, while negative value represents tensile ones).

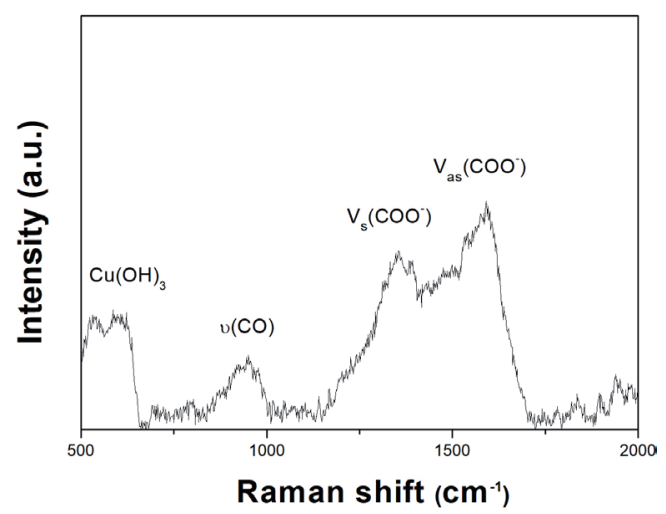

(b)

Fig. 7. Raman spectra obtained from the fractured surface of sheared $\mathrm{Cu}$-to- $\mathrm{Cu}$ joints subsequent to formic acid vapor pretreatment (a) with and (b) without Pt catalysis.

\section{Conclusions}

In this study, we propose a concept to improve direct $\mathrm{Cu}$ bonding through the increase in compressive residual stresses on the faying face using air plasma pretreatments. It is suggested that instead of surface activation, plasma-induced compressive stresses, which can be verified by XRD and nanoindentation responses, contributed to an effective interdiffusion and thus robust $\mathrm{Cu}$-to- $\mathrm{Cu}$ bonding. A joint strength higher than $30 \mathrm{MPa}$ can be obtained when thermal compression bonding was performed at $250{ }^{\circ} \mathrm{C}$ for 5 min under a bonding load of $10 \mathrm{MPa}$ in $\mathrm{N}_{2}$. Formic acid vapor catalyzed by Pt was developed for an efficient on-line deoxidation prior to thermal compression bonding. It was verified that Pt catalysis can certainly diminish organic residues. 


\section{Acknowledgments}

This work was supported by the Ministry of Science and Technology (Taiwan, R.O.C.) under contract Nos. NSC 101-2628-E-005-001-MY2 and 106-2221-E-005-028-MY3, for which the authors are grateful. This work was also supported by the "Innovation and Development Center of Sustainable Agriculture" from the Featured Research Center Program within the framework of the Higher Education Sprout Project by the Ministry of Education (Taiwan, R.O.C.).

\section{References}

1 W. T. Park, J. W. Jang, T. Clare, and L. Lin: Scripta Mater. 64 (2011) 733. https://doi.org/10.1016/ j.scriptamat.2010.12.024

2 V. Luminineau, F. Fournel, B. Imber, and F. Hodaj: ECS Trans. 75 (2016) 273. https://doi. org/10.1149/07509.0273ecst

3 E. J. Jang, J. W. Kim, B. Kim, T. Matthias, and Y. B. Park: Met. Mater. Int. 17 (2011) 105. https://doi. org/10.1007/s12540-011-0214-0

4 K. N. Chen, A. Fan, C. S. Tan, and R. Reif: J. Electron. Mater. 35 (2006) 230. https://doi.org/10.1007/ BF02692440

5 N. Matsuoka, M. Fujino, M. Akaike, and T. Suga: Int. Conf. Electronics Packaging/iMAPS All Asia Conf. (2015) 460. https://doi.org/10.1109/ICEP-IAAC.2015.7111058

6 T. Suga, A. Masakate, W. Yang, and N. Matsuoka: Int. Conf. Electronics Packaging (2014) 644. https://doi. org/10.1109/ICEP.2014.6826759

7 W. Yang, M. Akaike, M. Fujino, and T. Suga: Int. Conf. Electronics Packaging (2012) 147. https://doi. org/10.1109/ICEPT-HDP.2012.6474588

8 C. M. Liu, H. W. Lin, Y. S. Huang, Y. C. Chu, C. Chen, D. R. Lyu, K. N. Chen, and K. N. Tu: Sci. Rep. 5 (2015) 7934. https://doi.org/10.1038/srep09734

9 Y. P. Huang, Y. S. Chien, R. N. Tzeng, M. S. Shy, T. H. Lin, K. H. Chen, C. T. Chiu, J. C. Chiu, C. T. Chuang, W. Hwang, H. M. Tong, and K. N. Chen: IEEE Electron Device Lett. 34 (2013) 1551. https://doi.org/10.1109/ LED.2013.2285702

10 S. Y. Hsu, H. Y. Chen, and K. N. Chen: IEEE Electron Device Lett. 33 (2012) 1048. https://doi.org/10.1109/ LED.2012.2194769

11 C. S. Tan, D. F. Lim, S. G. Singh, S. K. Goulet, and M. Bergkvist: Appl. Phys. Lett. 95 (2009) 192108. https:// doi.org/10.1063/1.3263154

12 T. Sakai, N. Imaizumi, and S. Sakuyama: Inter. Conf. Electronics Packaging/iMAPS All Asia Conf. (2015) 464. https://doi.org/10.1109/ICEP-IAAC.2015.7111059

13 T. Sakai, N. Imaizumi, and T. Miyajumi: IEEE CPMT Symp. Japan (2012) 6523388. https://doi.org/10.1109/ ICSJ.2012.6523388

14 C. Ghica, L. C. Nistor, B. Mironov, and S. Vizireanu: ROM. Rep. Phys. 62 (2010) 329.

15 Y. Arai, M. Nimura, and H. Tomokage: Int. Conf. Electronics Packaging/iMAPS All Asia Conf. (2015) 468. https://doi.org/10.1109/ICEP-IAAC.2015.7111060

16 W. C. Oliver and G. M. Pharr: J. Mater. Res. 564 (1992) 1564. https://doi.org/10.1557/JMR.1992.1564

17 M. Gelfi, E. Bontempi, R. Robert, L. Armelao, and L. E. Depero: Thin Solid Films 450 (2004) 143. https://doi. org/10.1016/j.tsf.2003.10.059

18 W. L. Chan and E. Chason: J. Vac. Sci. Technol., A 26 (2008) 44. https://doi.org/10.1116/1.2812432

19 H. Y. Chen, Y. C. Lin, and J. S. Lee: Appl. Surf. Sci. 338 (2015) 113. https://doi.org/10.1016/j.apsusc.2015.02.112

20 P. H. Chiang, S. Y. Liang, J. M. Song, S. K. Huang, Y. T. Chiu, and C. P. Hung: Jpn J. Appl. Phys. 56 (2017) 035503. https://doi.org/10.7567/JJAP.56.035503

21 M. J. Aziz: Appl. Phys. Lett. 70 (1997) 2810. https://doi.org/10.1063/1.119066 